\title{
CHEMICAL PRE-TREATMENTS OF ALUMINIUM MATERIALS IN ORDER TO INCREASE SELECTED PROPERTIES OF SURFACE
}

\author{
Jaroslava Svobodova \\ J. E. Purkyne University in Usti nad Labem, Czech Republic \\ svobodova@fvtm.ujep.cz
}

\begin{abstract}
Chemical pre-treatment of material is the basic step for increasing higher corrosion resistance, better adhesion of the final organic coating or increasing the material surface wear. We can achieve this aim by using the chemical nanotechnology based pre-treatment (product based on compounds of $\mathrm{Zr}, \mathrm{F}, \mathrm{Si}, \mathrm{O}$ or PTFE). We tested several combinations of chemical pre-treatment on the aluminium sheet surface. The roughness of the surface is important due to the anchor profile of the material. We measured the surface roughness before and after application of chemical pre-treatment. All experimental samples were studied also using the SEM analysis. We observed and analysed the material surface due to the morphology of the surface and the layer appearance. The study of these new types of chemical pre-treatment is important, because it is necessary to describe the behaviour of the created layer eventually to find the weaknesses of these new types of chemical pre-treatment.
\end{abstract}

Keywords: chemical pre-treatment, aluminium materials, nanotechnology, SEM, surface roughness.

\section{Introduction}

Corrosion of metals is a spontaneous irreversible process of metallic material disruption due to their chemical and electrochemical reactions, which take place in their surrounding environment. The effect of corrosion occurs in each field of technical activity. Corrosion does not concern only metallic materials, but also non-metallic materials, for example, inorganic substances (glass, ceramics, and concrete) and organic substances (rubber, plastics), and others materials. Material damage with corrosion can be different, for example, from changes in appearance (colour changes, tarnish) to a complete disintegration of the material. Spontaneous process of corrosion is caused by the effort of the corrosion system (material - environment), which leads to the more probable state with a smaller free enthalpy [1-3].

We effort to improve also the material protection against corrosion attack with the development of the new treatments and discovering of the new technologies. We try to replace the convention methods that can be ineffective, uneconomical and environmentally unfriendly with these new technologies. Especially, we try to remove phosphating and chromating processes in the future. We can arrange also the evolving field of nanotechnologies among these technologies. We try to find suitable use of this field for different industrial processes and for different manufacturing sectors.

Nanolayers based on zirconium, titanium and other elements provide, for example, good conditions for adhesion between the final coating layer and the basic material. It is a form of the surface pre-treatment before the application of paints. To the technological advantages of the nanolayers belong:

- application at lower temperatures (room temperature),

- longer life time,

- less time consuming,

- have universal use for steel and aluminium material pre-treatments,

- good corrosion resistance comparable with phosphate,

- easier way of waste disposal [2-4].

The aim of the nanotechnology based pre-treatment is improvement of the material surface quality, increasing of corrosion resistance and thereby the lifetime of metallic materials.

This type of pre-treatment uses the principle of passivity. All sorts of the barrier effect of corrosion products and other substances are included under this term. Passivity based on oxide type is caused by the formation of a very thin nonporous layer that is caused by oxides and hydroxides. The layer is located at the interface metal - electrolyte and the creation of this layer is always connected with increasing of corrosion potential towards positive values. This phenomenon can cause higher corrosion resistance of metallic materials. We can name zirconium, titanium and aluminium as the 
examples of the metals. These metals have relatively low value of electrochemical nobility, but due to the ability of thin passivation layer creation their corrosion resistance is very good $[1 ; 5 ; 6]$.

The article is focused on the influence of the chemical pre-treatment applied on aluminium material in terms of exclusion of the chemical pre-treatment using the SEM analysis and surface roughness measurements. The layers created on the material surface use the principle of passivity. It is therefore a passivation layer formed on the surface by means of the sol-gel technology [4;7].

\section{Materials and chemical pre-treatments}

The aluminium sheet was used for the experiment as a basic material for coating and coating analyses. This is a deep-drawn rolled sheet of alloy AlMg3. We used four types of basic material $\mathrm{AlMg} 3$ with different treatment. We tested if the treatment of the basic material has some influence on the excluded layer. The plan of the experiment was prepared and the experimental samples were divided into the four groups due to the variant of the chemical pre-treatment and the treatment of the basic material. Each group contains 5 experimental samples to ensure the comparability. The description and designation of the experimental samples are shown in the Table 1.

Table 1

Description and designation of experimental samples

\begin{tabular}{|c|c|}
\hline Designation & Description \\
\hline A & Thermoforming sheet AlMg3 intermediate annealing to 4 mm \\
\hline B & $\begin{array}{c}\text { Thermoforming sheet AlMg3 without intermediate annealing, with the addition of } \\
\text { TiB and Be }\end{array}$ \\
\hline C & $\begin{array}{c}\text { Sheet AlMg3 without adding AlTi5B1 wire and AlBe5, intermediate annealing to } 4 \\
\text { mm }\end{array}$ \\
\hline D & Thermoforming sheet AlMg3 without intermediate annealing \\
\hline A1 & Material A - chemical pre-treatment with the use of the product NANO 1 \\
\hline A2 & Material A - chemical pre-treatment with the use of the product NANO 1 + PTFE \\
\hline A3 & Material A - chemical pre-treatment with the use of the product NANO 2 \\
\hline A4 & Material A - chemical pre-treatment with the use of the product NANO 2 + PTFE \\
\hline B1 & MaterialB - chemical pre-treatment with the use of the product NANO 1 \\
\hline B2 & Material B - chemical pre-treatment with the use of the product NANO 1 + PTFE \\
\hline B3 & MaterialB - chemical pre-treatment with the use of the product NANO 2 \\
\hline B4 & Material B - chemical pre-treatment with the use of the product NANO 2 + PTFE \\
\hline C1 & Material C - chemical pre-treatment with the use of the product NANO 1 \\
\hline C2 & Material C - chemical pre-treatment with the use of the product NANO 1 + PTFE \\
\hline C3 & Material C - chemical pre-treatment with the use of the product NANO 2 \\
\hline C4 & Material C- chemical pre-treatment with the use of the product NANO 2 + PTFE \\
\hline D1 & Material D - chemical pre-treatment with the use of the product NANO 1 \\
\hline D2 & Material D - chemical pre-treatment with the use of the product NANO 1 + PTFE \\
\hline D3 & Material D - chemical pre-treatment with the use of the product NANO 2 \\
\hline D4 & Material D - chemical pre-treatment with the use of the product NANO 2 + PTFE \\
\hline
\end{tabular}

The coating process itself used four types of technologies:

- Zirconium nanopassivating products NANO 1 and NANO 2: fluid highly effective products intended for creating of nanomolecular coatings, which protect against corrosion different metal surfaces using the sol-gel (SG) process. The sol-gel process is based on synthesis and stabilization of the nanoparticles. This product is chrome-free and it is ideal for protection of aluminium and also steel surfaces after cleaning. Its special organic elements support adhesion before the final coatings application. The passivating layer is colourless. Phase composition of the chemical is $\mathrm{ZrF} 4$ and different modifications of $\mathrm{SiO} 2$, which responds to tetraetoxysilan bath for the sol-gel method. Conversion coating is created with zirconium particles, which are on the material surface in the form of zirconium dioxide. The thickness of the coating reaches tens of nanometres $(\approx 30-50 \mathrm{~nm})$. The difference between these two products is in the application possibility, and there are a little bit different technological conditions of the use. 
- Teflon product PTFE: product based on the finest fluor polymeric particles; the basis is PTFE (polytetrafluorethylen - teflon). This product creates on the material surface tough oil film with thickness $20-25 \mu \mathrm{m}$ and causes a significant reduction of frictional (surface) resistance.

Each technology has its own specific requirements for the application parameters. It means concentration of the nanoproduct, $\mathrm{pH}$, time and temperature of application, time and temperature of drying at the end of the process. The process of application is shown in Figures 1-4.

Alkaline degreasing: application parameters -2 component product deployed in demineralised water, compound 1: 2-15 g. $1^{-1}$, compound: $2-10 \mathrm{~g} \cdot 1^{-1}$; density - compound $1:$ ca. $1.4 \mathrm{~g} \cdot 1^{-1}$, compound 2: ca. $1.0 \mathrm{~g} \cdot 1^{-1}$; state - two liquids; temperature of application $-55^{\circ} \mathrm{C}$; treatment time - immersion 5 minutes; description of the product - it is an alkaline degreasing liquid containing bicomponent pickling and degreasing agent for aluminium and its alloys. NANO 1: zirconium nanopassivating product NANO $1-1$ component product deployed in demineralised water, 20-40 g. $1^{-1}$; density -ca. $1 \mathrm{~g} / \mathrm{ml}$;state -liquid; temperature of application - room temperature; treatment time - immersion 2 minutes; $\mathrm{pH}$ value -5.2 ; drying temperature $-150^{\circ} \mathrm{C}, 2$ minutes; description of the product - liquid highly efficient zirconium product designed for creating nanomolecular surfaces protecting against corrosion various metal surfaces using the sol-gel processes. It is chromium-free, ideal for protection of steel and aluminium surfaces. NANO 2: zirconium nanopassivating product NANO $2-1$ component product deployed in demineralised water, $10-30 \mathrm{~g} \cdot \mathrm{l}^{-1}$; density $-\mathrm{ca} .1 .1 \mathrm{~g} \cdot \mathrm{ml}^{-1}$; state liquid; temperature of application $-15-50{ }^{\circ} \mathrm{C}$, depends on concrete application; treatment time immersion 2 minutes; $\mathrm{pH}$ value -4.2 ; drying temperature $-150{ }^{\circ} \mathrm{C}, 2$ minutes; description of the product - it is a product without the presence of chromium, intended for corrosion protection. The product can be used on aluminium and galvanized surfaces and makes them pre-treated with increased corrosion resistance. PTFE: product based on the finest fluor polymeric particles -1 component product deployed in demineralised water, $8-10 \mathrm{~g} \cdot \mathrm{l}^{-1}$; density - ca. $1.5 \mathrm{~g} \cdot \mathrm{ml}^{-1}$; state - liquid; temperature of application $-60^{\circ} \mathrm{C}$; treatment time - immersion 10-12 minutes; $\mathrm{pH}$ value - 7.5-8.5; drying temperature $-150^{\circ} \mathrm{C}, 30$ minutes; description of the product - This is one-component liquid composition for surface treatment of aluminium. The product creates a very tough greasy film that causes significant reduction in frictional resistance.

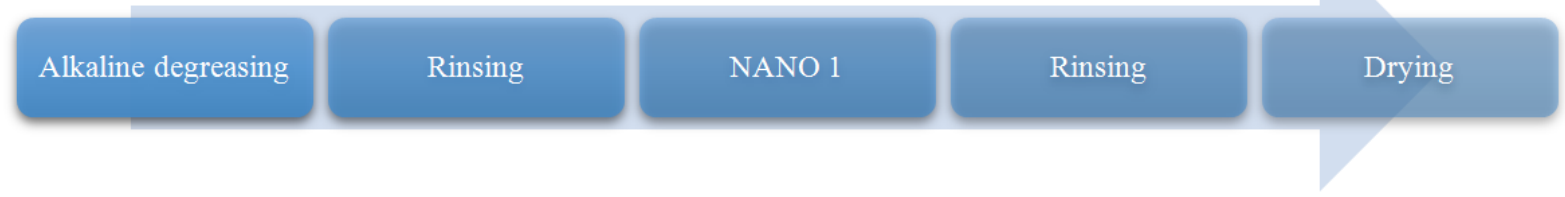

Fig. 1. Technological process variant 1 (samples A1, B1, C1, D1)

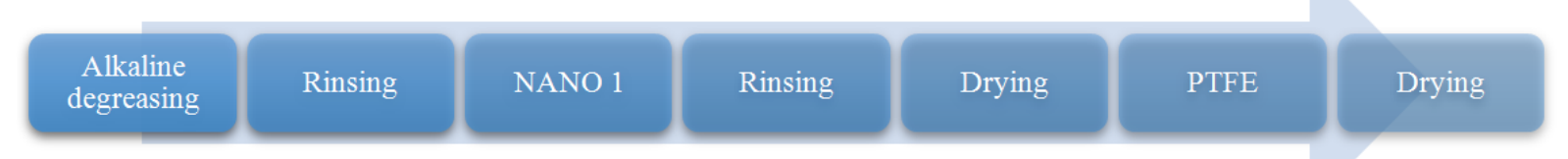

Fig. 2. Technological process variant 2 (samples A2, B2, C2, D2)

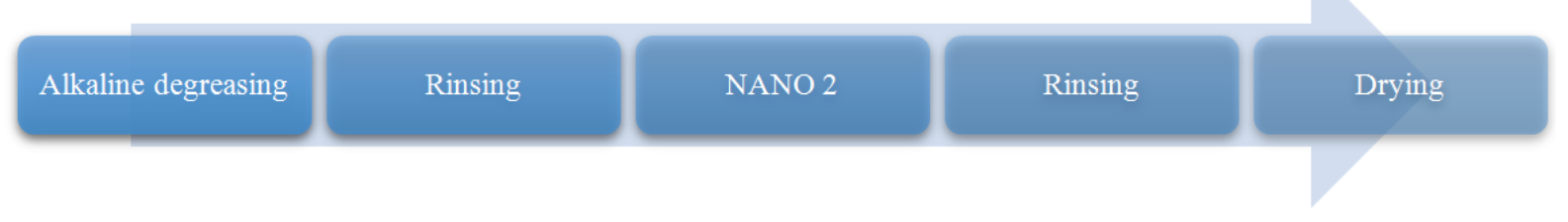

Fig. 3. Technological process variant 3 (samples A3, B3, C3, D3) 


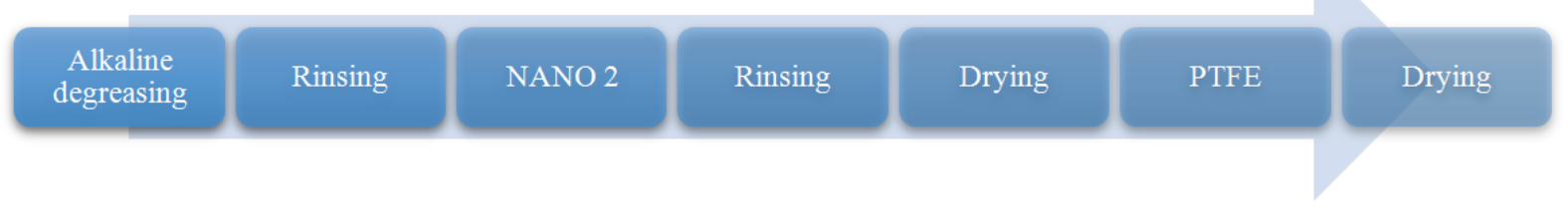

Fig. 4. Technological process variant 4 (samples A4, B4, C4, D4)

\section{Roughness analysis}

We used the following parameters - Rz (mean roughness depth) and Rt (total height of the roughness profile) for evaluation of the surface roughness.

The surface roughness measurement was performed according to the standard CSN EN ISO 4287. The first measurement was performed on the basic material before chemical pre-treatment and after that the experimental samples after application of chemical products were measured. The surface roughness measurement was performed at the same conditions as by the basic material. We performed 20 measurements on the surface of each sample. The results of individual roughness measurements are shown in figures below (Fig. 5-8). The surface roughness analysis is important because these pretreatments are suitable as a base before the application of paints. So, it is necessary to have good conditions for paint adhesion. These pre-treatments provide good anchor profile and good corrosion resistance of the basic material, which improve the lifetime of the material. There are listed the average values of the surface roughness measurement in the graphs.

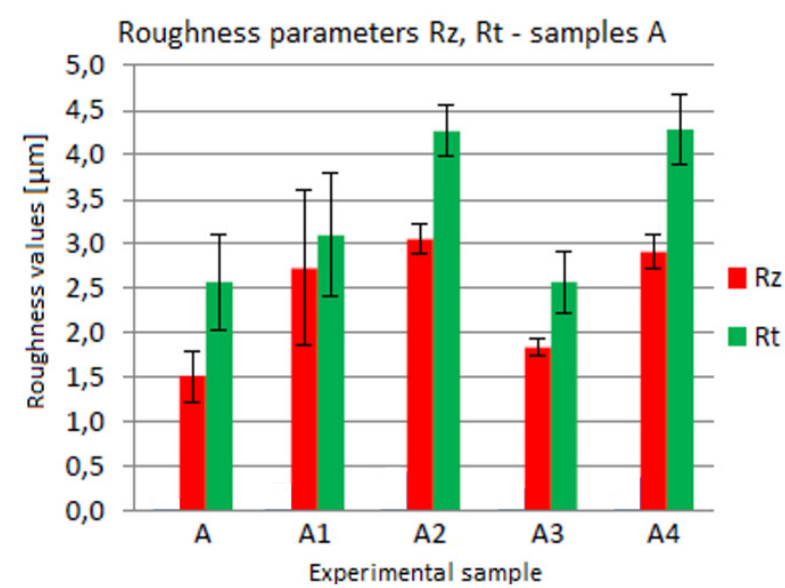

Fig. 5. Surface roughness measurement samples variant $\mathbf{A}$

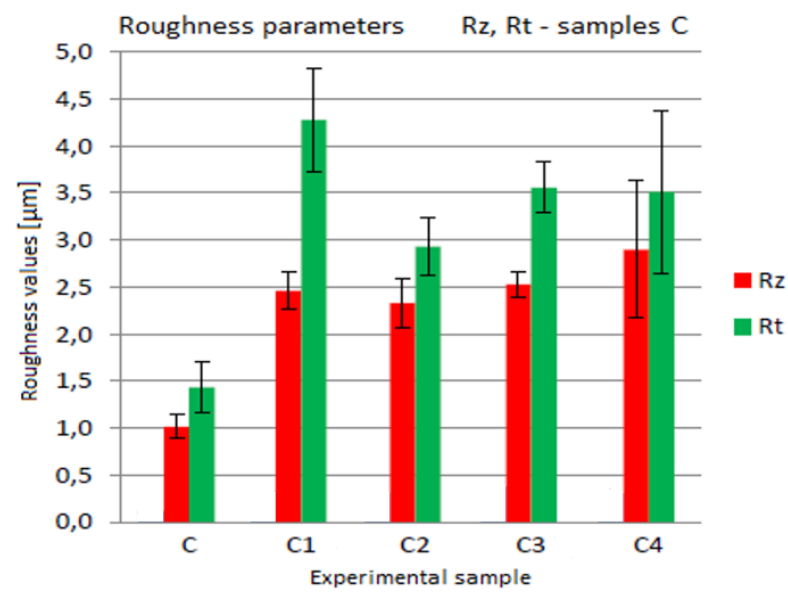

Fig. 7. Surface roughness measurement samples variant $\mathbf{C}$

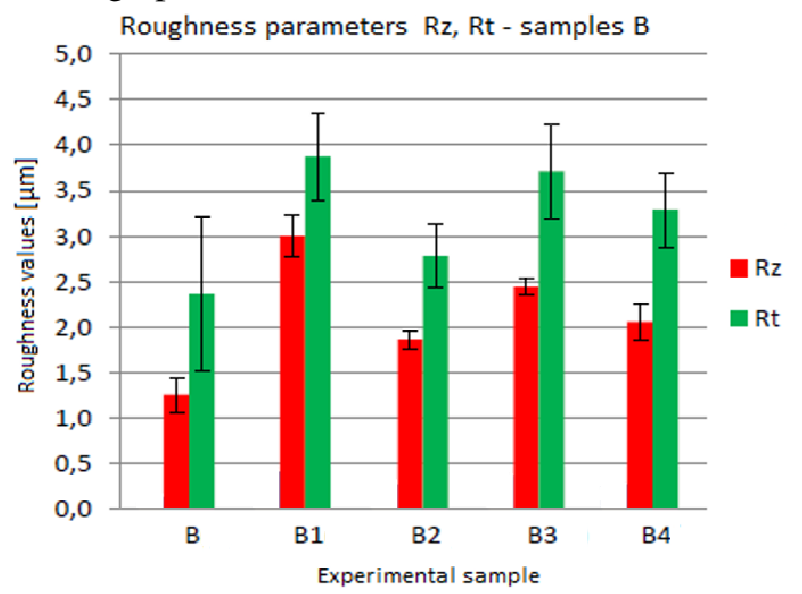

Fig. 6. Surface roughness measurement samples variant $B$

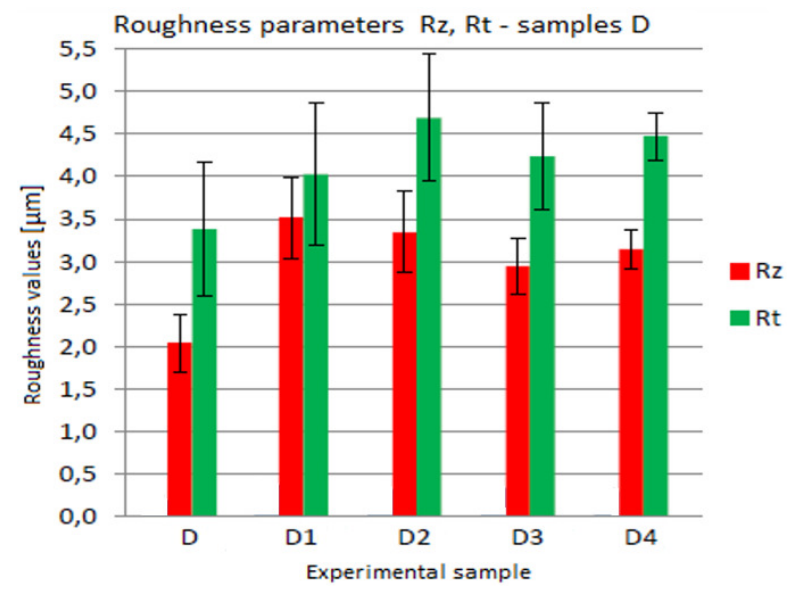

Fig. 8. Surface roughness measurement samples variant $D$ 


\section{SEM analysis}

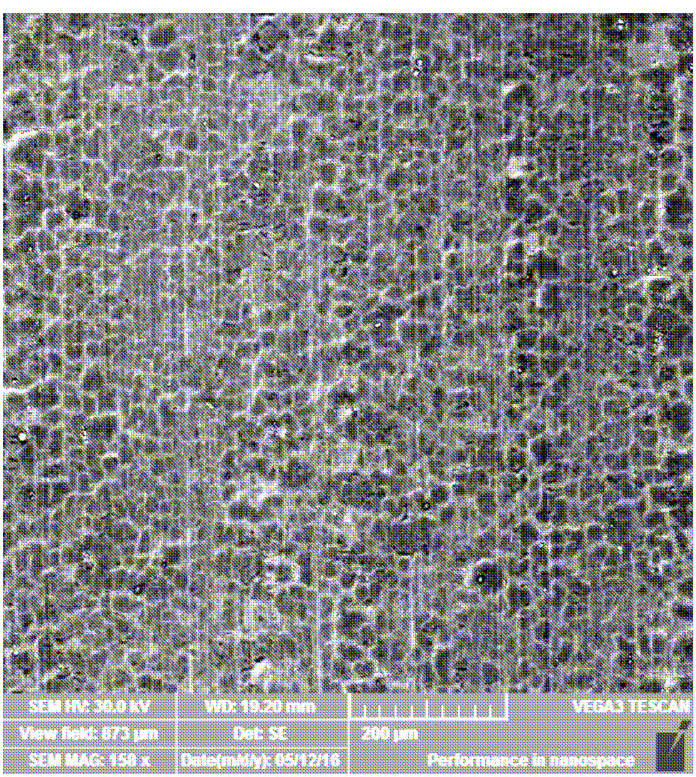

Fig. 9. Experimental sample group A

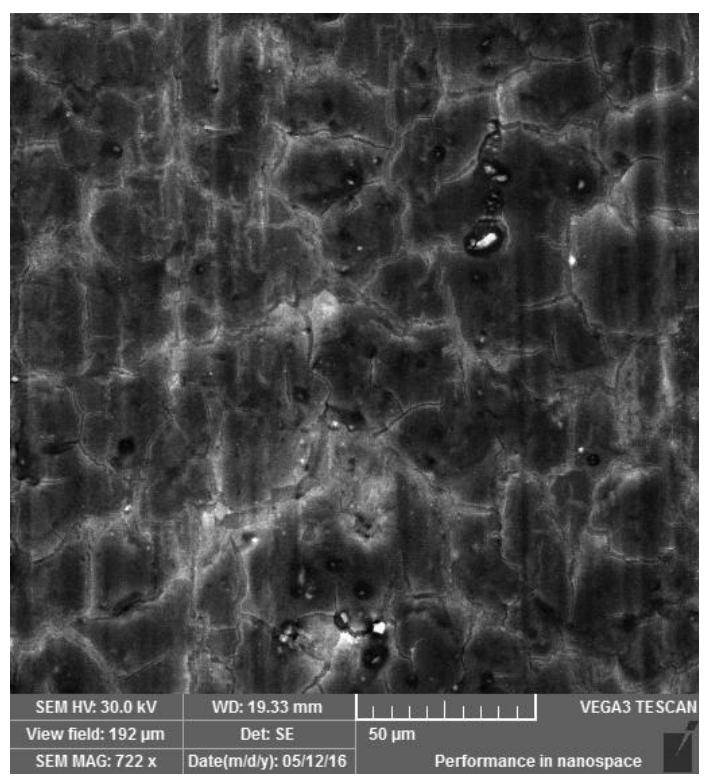

Fig. 10. Experimental sample group B

Variant A and variant B of the experimental samples (Fig. 9 and Fig. 10) are characteristic by excluding of the coherent coating layer. There is a problem with cracks that we can observe on the surface. This is probably due to the drying temperature and the stress in the layer during the drying process.

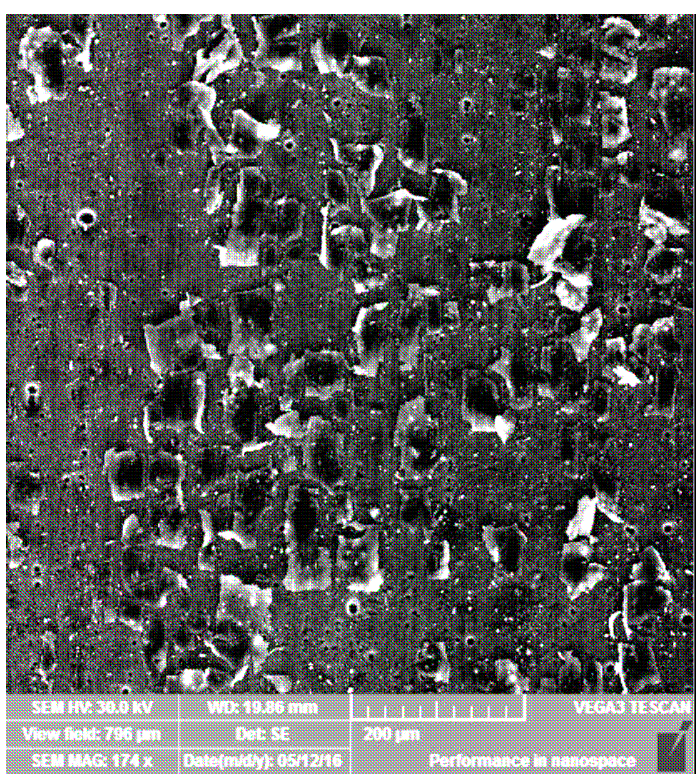

Fig. 11. Experimental sample group C

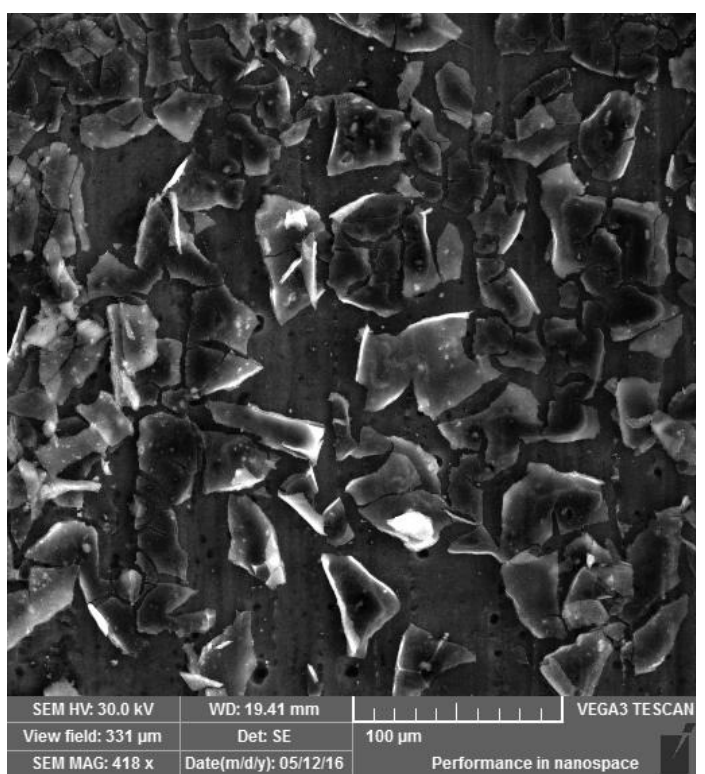

Fig. 12. Experimental sample group D

Variant $\mathrm{C}$ and variant $\mathrm{D}$ of the experimental samples (Fig. 11 and Fig. 12) have another character of excluded layers. Cracking and delamination are visible on the surface of these two coating variants. This fact is caused by using of another passivating product. The product NANO 2 is unsuitable for pre-treatment of aluminium materials. The layer is very uneven and it will not perform the corrosion protection function. It can also cause problems after application of the final coating, when it could cause its peeling.

\section{Conclusions}

Surface roughness measurement - we could find the influence of each chemical pre-treatment with this analysis. We compared all results from this measurement and concluded what effect 
individual chemical pre-treatments had to the change of the roughness profile. It is evident that the chemical pre-treatment methods, without exceptions, increase both observed roughness parameters. This is due to the first step of the chemical pre-treatment (alkaline degreasing), which partially dissolves the base material and increases the surface roughness and the material profile. The rough surface of the basic material helps to this fact. The chemical is concentrated in the recesses of the profile and significantly dissolves the basic material. This phenomenon occurs in all samples.

SEM analysis - we can observe a uniformly excluded coating from the images obtained by the SEM analysis of the first two samples (variant A and B). We see cracking of the coating for these two samples. This is probably due to drying of the samples. A similar style of exclusion can be observed on the samples $\mathrm{C}$ and $\mathrm{D}$. These two samples do not show a continuous coating of the layer compared with the previously described samples. We see rather the remnants of the coating that form the "scales" distributed over the surface.

We can say that the processes of chemical pre-treatment have a significant effect on the surface roughness of the base material from the results of the experiment. Alkaline degreasing has the main effect of changing the surface roughness, which partially dissolves the surface of the base material and thus improves the surface roughness. This could have a positive impact on the processes of paint that need surface roughness of the material. Furthermore, the results imply that the terms of the exclusion coating based on the nanotechnology is the best utilizing method in order alkaline degreasing + NANO1 + PTFE. The product NANO 2 is unsuitable for commercial use, because the material does not provide corrosion protection or suitable conditions for capturing of the paint.

\section{References}

1. Philip A., Schweitzer P.E. Paint and Coatings: Aplications and Corrosion Resistance. Corrosion Technology, Taylor\&Francis, Vol. 23, 2005, p. 672.

2. Balgude D., Sabnis A. Sol-gel derived hybrid coatings as and environment friendly surface treatment for corrosion protection of metals and their alloys. Sol-Gel Sci Technol,Springer, Vol. 64, 2012, pp. 124-134.

3. Svobodova J. SEM and EDS Analysis Used in Evaluation of Chemical Pre-treatment Based on Nanotechnology. Manufacturing Technology, Journal for Science, Research and Production,Vol. 14, No. 3,2014,pp. 461-467.

4. Novotna P., Krysa J., Maixner J., Kluson P., Novak P. Photocatalytic activity of sol-gel TiO2 thin films deposited on soda lime glass and soda lime glass precoated with a $\mathrm{SiO} 2$ layer. Surface \& Coatings Technology, Vol. 204, 2010. pp. 2570-2575.

5. Svobodova J. Evaluation of New Type of Chemical Pre-treatment Applied on Low-carbon Steel Substrate Using SEM and EDS Analysis.Engineering for Rural Development,14th International Scientific Conference, 2015,[online][31.01.2016]. Available at: http://www.tf.llu.lv/conference/proceedings2015.

6. Svobodova J., Kraus P., Cais J., Lattner R. Research of Chemical Pre-treatment Created by Solgel Process on the Polished Surface of Aluminium Substrate. Manufacturing Technology, Journal for Science, Research and Production,Vol. 16, No. 1,2016, pp. 259-264.

7. Svobodova J., Kraus P. Influence of Chemical Pre-treatments Nanotechnology Based Applied to the Al Sheet on the Roughness and Morphology of the Surface. Manufacturing Technology, Journal for Science, Research and Production, Vol. 15, No. 4, 2015, pp. 714-720. 